\title{
Patient preferences for using technology in communication about symptoms post hospital discharge
}

\author{
Kim E. Alexander ${ }^{1,2^{*}}$ (D) Theodora Ogle ${ }^{1}$, Hana Hoberg ${ }^{1}$, Libbie Linley ${ }^{2}$ and Natalie Bradford ${ }^{1}$
}

\begin{abstract}
Background: Technology is increasingly transforming the way we interact with others and undertake activities in our daily lives. The healthcare setting has, however, not yet realised the potential of technology solutions to facilitate communication between patients and healthcare providers. While the procedural and policy requirements of healthcare systems will ultimately drive such solutions, understanding the preferences and attitudes of patients is essential to ensure that technology implemented in the healthcare setting facilitates communication in safe, acceptable, and appropriate ways. Therefore, the purpose of this study was to examine patient preferences for using technology to communicate with health service providers about symptoms experienced following discharge from the hospital.

Methods: Primary data were collected from patients admitted to a large metropolitan hospital in Australia during three consecutive months in 2018. Participants were asked about their daily use of technology including use of computers, email, phone, text messaging, mobile applications, social media, online discussion forums, and videoconference. They were then asked about their use of technologies in managing their health, and preferences for use when communicating about symptoms with health service providers following discharge from hospital.

Results: Five hundred and twenty-five patients with a wide range of differing clinical conditions and demographics participated. Patients indicated they used a range of technologies in their everyday lives and to manage their health. Almost $60 \%$ of patients would prefer to return to hospital if they were experiencing symptoms of concern. However, if patients experienced symptoms that were not of concern, over $60 \%$ would prefer to communicate with the hospital via telephone or using technology. Admitting condition, income, and age were significantly associated with preferences for communication about symptoms following hospital discharge.
\end{abstract}

Conclusions: Patients have varied preferences for communicating with their health service providers post-hospital discharge. Findings suggest that some, but not all patients, would prefer to use technology to traditional methods of communicating with the healthcare team. Health services should offer patients multiple options for communicating about their recovery to ensure individual needs are appropriately met.

Keywords: Technology, Digital health, Symptoms, Communication, Health services, Patient preference, Patient discharge, Text messaging, Videoconferencing, Mobile applications

\footnotetext{
* Correspondence: k.alexander@qut.edu.au

${ }^{1}$ Queensland University of Technology (QUT), Centre for Healthcare

Transformation, Cancer \& Palliative Care Outcomes Centre, Brisbane, Australia

${ }^{2}$ St Vincent's Private Hospital Northside, Brisbane, Australia
}

\section{$\triangle B M C$}

C C The Author(s). 2021 Open Access This article is licensed under a Creative Commons Attribution 4.0 International License, which permits use, sharing, adaptation, distribution and reproduction in any medium or format, as long as you give appropriate credit to the original author(s) and the source, provide a link to the Creative Commons licence, and indicate if changes were made. The images or other third party material in this article are included in the article's Creative Commons licence, unless indicated otherwise in a credit line to the material. If material is not included in the article's Creative Commons licence and your intended use is not permitted by statutory regulation or exceeds the permitted use, you will need to obtain permission directly from the copyright holder. To view a copy of this licence, visit http://creativecommons.org/licenses/by/4.0/. The Creative Commons Public Domain Dedication waiver (http://creativecommons.org/publicdomain/zero/1.0/) applies to the data made available in this article, unless otherwise stated in a credit line to the data. 


\section{Background}

Information and communication technologies (ICT), such as telehealth, electronic patient-reported outcome measures (ePROMs), and patient portals for electronic medical records (EMR), hold great promise in enabling more efficient and effective healthcare service delivery [1]. Despite recognition that ICT enhances communication possibilities, health services have not yet realised the full potential of technologies in practice [2]. Factors identified by healthcare workers critical to adoption include: ease of technology use, integration with workflow, evidence of positive impact on patient outcomes, ability to interact with others, data security, and resourcing [3-6]. Where ICT is used in clinical practice, it has primarily been unilateral in that the health service or clinician initiates communication with patients, or uses technology in health management without patient involvement [7]. With growing demands on health services, and as patients are increasingly encouraged to engage more in self-management of their health [8], understanding patient preferences for initiating communication with health service providers warrants exploration.

Information and communication technologies are now part of almost every aspect of daily life. Alongside the proliferation of ICT across the world is the rise in their use in healthcare [9]. With the emergence of the COVID-19 pandemic, telehealth remote monitoring and consultation are now commonplace [10]. Other technologies such as ePROMs assist in systematically and comprehensively monitoring and improving symptoms resulting in reduced data entry burden for clinicians [11-13]. Patient portals for EMRs can assist with clinical history documentation, clinician prescribing, and messaging between healthcare staff and patients [7]. A review of studies about patient preferences for discharge communication found that research to date has only evaluated the provision of discharge information at the time of discharge (e.g. written or verbal summaries provided by the health service provider) [14]. Only one study has surveyed patients with hypertension in the outpatient clinic setting about use and preferences of ICTs for information and communication. Still, participants were not asked about their preferences relative to more traditional modes of communication (i.e., inperson or via a telephone call) [15]. No studies have been conducted about patient preferences for using ICTs to facilitate communication between patients and health service providers following their discharge from hospital.

The time following discharge from an admission to hospital is of great importance to recovery. Patients with different clinical conditions may experience a range of symptoms following discharge. It can be difficult for some patients to determine which symptoms are of clinical significance (i.e., whether a symptom warrants intervention by their healthcare provider) [16]. A symptom that is not of particular concern for a patient may be of significance to their healthcare. The ability for effective two-way communication about symptoms is, therefore, of great importance to the patient and the clinician. With the increasing availability of digital technologies, the possibility exists for patients to communicate about health needs electronically from the comfort of their homes, avoiding unnecessary trips to the hospital, saving both time, travel, and costs [17]. Little is known about individuals' preference for communicating with health service providers through the use of digital technologies. The purpose of this paper, therefore, is to report on patient experience with, and preferences for, using a variety of technologies to communicate with health service providers about symptoms following discharge from the hospital. Further we seek to explore demographic factors that may be helpful in identifying patients with unique communication preferences.

\section{Methods \\ Design and participants}

Patients arriving for a planned admission to a metropolitan hospital in Queensland during three consecutive months in 2018 were surveyed in the hospital admission area about their technology use and preferences. Patients were given verbal and written information about the study and provided with a paper survey. Verbal and implied consent was obtained from all participants. Patients interested in participating did so by voluntarily and anonymously completing the survey and returning it to the research team via collection boxes. This form of informed consent was used because of the low-risk nature of the study, to reduce time pressures in participation, and to ensure participant anonymity. A waiver of written consent for this study met national regulations and was approved by the Institutional Research Ethics Committee.

\section{Measures}

A descriptive survey was developed for this study and is provided as Additional File 1. The survey included selfreported questions about current use of technology, and preferences for the use of technology when communicating with their healthcare team post-hospital discharge about symptoms. The questions about the use of technology asked patients about their use of 11 types of digital technologies in their general day to day activities, and for managing health, as well as their future interest in using digital technologies. Participants could answer with one of three options: 1) 'I currently use', 2) 'I don't use but would be interested in using', and 3) 'I don't use and don't have any interest in using'. The survey also asked participants to rank their preference of nine options for communicating about symptoms with the healthcare team following discharge. 
The survey included self-reported questions about patient demographic and clinical characteristics. These variables were asked because they are common demographic and clinical variables collected by most medical record systems and may be useful in identifying people with unique communication preferences. For most characteristics (i.e., gender, age, highest educational training, language spoken at home, employment, annual household income, living arrangements, and responsibilities for others at home), participants were asked to select a category of those presented in Table 1. For the characteristic 'geographic area of residence', participants were asked to provide their postal (zip) code. The code was then categorised based on the Australian Standard Geographical Classification System (i.e., 'metropolitan', 'inner regional', 'outer regional/remote'). Participants were asked to write in free-text their condition requiring treatment and planned treatment. Responses were then categorised by two clinicians based on the hospital speciality areas (i.e., 'orthopaedic', 'cardiac', 'oncological', 'gastrointestinal' or 'other'), and if the treatment involved 'surgery' or was for 'investigation or medical care', respectively. Members from the hospital patient advisory group provided input about the survey readability, and the survey was pilot tested with 33 admitted medical patients. Minor wording modifications were made to the survey after testing. Responses collected during the pilot testing were excluded in the final analyses.

\section{Data analysis}

SPSS (Version 25) was used to perform data analyses. Descriptive statistics were primarily used in this study to describe the responses to most survey questions. To compare patient preferences for using digital technologies in relation to more traditional methods for communicating with health service providers following discharge from hospital, crude relationships between patient characteristics and communication preferences, categorised as 'in-person', 'by telephone' or 'through digital technology', were established using Chi-square analyses. Multinominal logistic regression was used to identify potentially significant demographic predictors of various communication preferences (telephone compared to in-person and digital technology compared to in-person) and included significant $(p<0.05)$ covariates identified in the bivariate analyses. Age and gender were retained in the model as historical variables of interest relating to preferencing. Relative Risk Ratios (RRR), Confidence Intervals (CI), and $p$-values are presented. As the focus of the analyses was exploratory, not to test or build a predictive model, standard (simultaneous) multiple regression analysis was used over other regression models and associated model building techniques.

\section{Results}

During the period of the survey there were 2401 unique planned admissions at the hospital. A total of 603 surveys were returned. Due to significant missing data about their current technology use and preferences 78 surveys were removed. The results for this study included responses from 525 patients with a planned admission to the hospital. Table 1 provides the characteristics of the sample. There was an approximately equal distribution of male $(n=244,51 \%)$ and female $(n=238,49 \%)$ patients, and the majority $(n=294,70 \%)$ were aged over 50 years, and most $(n=503,98 \%)$ spoke English at home. Only $26.4 \%$ of participants lived in a regional/remote area (i.e., an area that is more than a one-hour drive to the hospital). Many ( $n=285,54 \%)$ had completed vocational or postgraduate studies and a third $(n=152,33 \%)$ had an annual household income above 100,000 AUD. The majority lived with other people $(n=456$, $89 \%)$, but did not have responsibilities for children $(n=393$, $76 \%)$ or elders $(n=485,94 \%)$ at home. Reasons for admission were for surgery (e.g., knee replacement, breast cancer surgery) ( $n=326,68 \%$ ) or for investigational procedures and medical care (e.g., angiogram, cystoscopy) $(n=153,32 \%)$. Patients were admitted for a variety of conditions including gastrointestinal $(n=111,21 \%)$, orthopaedic $(n=142,14 \%)$, cardiac $(n=75,14 \%)$, and oncological $(n=41,8 \%)$.

Patients reported using a range of technologies as part of their general day to day activities (Table 2). The most frequently reported use was mobile phone $(n=495$, 97\%), text messaging $(n=454,93 \%)$, email $(n=452$, $93 \%)$, and the internet or websites $(n=451,93 \%)$. The least frequently used was online discussion groups or forums $(n=152,40 \%)$. Patients also reported high use of technology to assist in managing their health (see Table 2). For example, the most frequently reported use was mobile phone $(n=365,82 \%)$, internet/websites $(n=320$, $78 \%)$, email $(n=325,93 \%)$, a laptop or desktop computer $(n=317,74 \%)$, and text messaging $(n=275,76 \%)$. Using a tablet or mobile phone application to assist in managing health was the most frequently reported technology to be of interest to those not currently using $(n=70,20 \%)$. However, across all technologies, more patients were not interested than those who were interested in using each technology.

Patient-ranked communication preferences regarding symptoms post-discharge from the hospital for a planned admission are presented in Table 3. For symptoms of little concern, telephoning the hospital was the most common first preference $(n=193,37 \%)$, followed by attending the hospital in-person $(n=179,34 \%)$. Approximately $30 \%(n=160)$ of patients ranked a type of technology as their first preference for communication about symptoms that were of little concern. For symptoms of concern, in-person communication was the most common preference $(n=305,58 \%)$, followed by 
Table 1 Characteristics of patients that presented to hospital for a planned admission and participated in the study

\begin{tabular}{|c|c|c|c|}
\hline Characteristic & & $\begin{array}{l}\text { Respondents } \\
(n=525)\end{array}$ & $\%$ \\
\hline \multirow[t]{2}{*}{ Gender } & Male & 244 & 50.6 \\
\hline & Female & 238 & 49.4 \\
\hline \multirow[t]{5}{*}{ Age group (years) } & $18-30$ & 28 & 6.7 \\
\hline & $31-50$ & 97 & 23.2 \\
\hline & $51-65$ & 136 & 32.5 \\
\hline & $66-80$ & 135 & 32.2 \\
\hline & $81+$ & 23 & 5.5 \\
\hline \multirow[t]{3}{*}{ Geographic area of residence } & Metropolitan & 353 & 73.5 \\
\hline & Inner regional & 98 & 20.4 \\
\hline & Outer regional/remote & 29 & 6.0 \\
\hline \multirow[t]{5}{*}{ Condition requiring treatment } & Orthopaedic & 142 & 27.0 \\
\hline & Cardiac & 75 & 14.3 \\
\hline & Oncological & 41 & 7.8 \\
\hline & Gastrointestinal & 111 & 21.1 \\
\hline & Other & 74 & 14.1 \\
\hline \multirow[t]{2}{*}{ Planned treatment } & Surgery & 326 & 68.1 \\
\hline & Investigation/medical care & 153 & 31.9 \\
\hline \multirow[t]{3}{*}{ Highest Educational Training } & School & 229 & 44.5 \\
\hline & Vocational & 154 & 30.0 \\
\hline & Tertiary & 131 & 25.5 \\
\hline \multirow[t]{2}{*}{ Language spoken at home } & English & 503 & 97.9 \\
\hline & Other & 11 & 2.1 \\
\hline \multirow[t]{3}{*}{ Employment } & Employed & 284 & 55.4 \\
\hline & Unemployed & 19 & 3.7 \\
\hline & Retired & 210 & 40.9 \\
\hline \multirow[t]{2}{*}{ Annual Household Income (AUD) } & $<100,000$ & 314 & 67.4 \\
\hline & $\geq 100,000$ & 152 & 32.6 \\
\hline \multirow[t]{2}{*}{ Living arrangements } & Lives with others & 456 & 88.9 \\
\hline & Lives alone & 57 & 11.1 \\
\hline \multirow[t]{2}{*}{ Responsibilities for children at home } & No & 393 & 76.3 \\
\hline & Yes & 122 & 23.7 \\
\hline \multirow[t]{2}{*}{ Responsibilities for elders at home } & No & 485 & 94.2 \\
\hline & Yes & 30 & 5.8 \\
\hline
\end{tabular}

communicating by telephone $(n=168,32 \%)$. Communicating with any other technologies was the first preference by only $10 \%(n=49)$ of respondents. In terms of the types of technology, the least common preferred option for both symptoms of low and higher concern was for online discussion forums.

Bivariate analyses (Table 4) identified significant associations between several variables. Age $(p=.0001)$, condition requiring treatment $(p=.02)$, admitting medical condition $(p=.02)$, employment $(p=.0001)$, and household income $(p=.01)$ were associated with differing preferences for communicating about symptoms that were not of concern following hospital discharge. Type of condition requiring treatment was the only variable associated with preferences for communicating about symptoms that were of concern $(p=.01)$.

In the multivariable analyses, after controlling for salient covariates (i.e., those identified through bivariate analyses as well as age and gender), the admitting condition, income, and age remained significantly associated with communication preferences about symptoms following hospital discharge (Table 5). Type of treatment 
Table 2 Use of technology in general daily activities and to manage health

\begin{tabular}{|c|c|c|c|c|c|c|c|c|c|c|c|c|}
\hline & \multicolumn{6}{|c|}{ Use of technology in general daily activities } & \multicolumn{6}{|c|}{ Use of technology to manage health } \\
\hline & \multicolumn{2}{|c|}{$\begin{array}{l}\text { Currently } \\
\text { use }\end{array}$} & \multicolumn{2}{|c|}{$\begin{array}{l}\text { Do not use but } \\
\text { interest in using }\end{array}$} & \multicolumn{2}{|c|}{$\begin{array}{l}\text { Do not use and no } \\
\text { interest in using }\end{array}$} & \multicolumn{2}{|c|}{$\begin{array}{l}\text { Currently } \\
\text { use }\end{array}$} & \multicolumn{2}{|c|}{$\begin{array}{l}\text { Do not use but } \\
\text { interest in using }\end{array}$} & \multicolumn{2}{|c|}{$\begin{array}{l}\text { Do not use and no } \\
\text { interest in using }\end{array}$} \\
\hline & $\bar{n}$ & $\%$ & $\mathrm{n}$ & $\%$ & $\mathrm{n}$ & $\%$ & $\bar{n}$ & $\%$ & $\bar{n}$ & $\%$ & $\bar{n}$ & $\%$ \\
\hline Laptop or desktop computer & 430 & 89.2 & 15 & 3.1 & 37 & 7.7 & 317 & 74.2 & 41 & 9.6 & 69 & 16.2 \\
\hline Tablet & 321 & 75.5 & 46 & 10.8 & 58 & 13.6 & 204 & 56.4 & 72 & 19.9 & 86 & 23.8 \\
\hline Internet or websites & 451 & 93.2 & 8 & 1.7 & 25 & 5.2 & 320 & 77.7 & 34 & 8.3 & 58 & 14.1 \\
\hline Email & 452 & 93.0 & 13 & 2.7 & 21 & 4.3 & 325 & 77.6 & 38 & 9.1 & 56 & 13.4 \\
\hline Mobile phone & 495 & 97.2 & 4 & 0.8 & 10 & 2.0 & 365 & 82.2 & 31 & 7.0 & 48 & 10.8 \\
\hline Home phone & 321 & 73.0 & 6 & 1.4 & 113 & 25.7 & 194 & 54.6 & 25 & 7.0 & 136 & 38.3 \\
\hline Text messaging & 454 & 93.2 & 10 & 2.1 & 23 & 4.7 & 275 & 70.5 & 50 & 12.8 & 65 & 16.7 \\
\hline Mobile phone or tablet applications & 360 & 82.8 & 25 & 5.7 & 50 & 11.5 & 191 & 54.4 & 70 & 19.9 & 90 & 25.6 \\
\hline Online social networking services & 328 & 73.8 & 9 & 2.0 & 107 & 24.1 & 126 & 37.7 & 32 & 9.6 & 176 & 52.7 \\
\hline Online discussion group or forum & 152 & 40.2 & 37 & 9.8 & 189 & 50.0 & 81 & 25.2 & 53 & 16.5 & 188 & 58.4 \\
\hline Tele/video conferencing & 189 & 47.8 & 57 & 14.4 & 149 & 37.7 & 67 & 21.1 & 75 & 14.3 & 175 & 55.2 \\
\hline
\end{tabular}

received and employment were not included in the multivariable model because of the potential for multicollinearity with condition receiving treatment and annual household income, respectively. For symptoms not of concern, those aged $66-80$ years had a decreased preference for using technology to communicate than inperson compared to those aged between 51 and 65 years (RRR 0.40; CI 0.19, 0.83). Also, having either a cardiac or 'other' condition compared to having an orthopaedic condition was associated with decreased preference for in-person communication than a telephone call (RRR 0.19; CI 0.08-0.45, RRR 0.44; CI 0.20, 0.98, respectively). Having a household income of more than 100,000 AUD per year was associated with increased preference for telephone and technology than in-person modes of communication about symptoms of low concern (RRR 2.43; CI 1.25, 4.74, RRR 2.09; CI 1.08, 4.07, respectively). In comparison to those aged between 51 and 65 years, those aged over 80 years had a greater preference for telephone than in-person to communicate about symptoms of concern (RRR 2.72; CI 1.01, 9.34). Lastly, patients with gastrointestinal conditions had a decreased preference for in-person communication than using technology to communicate about symptoms of concern compared to patients with orthopaedic conditions (RRR 0.28; CI 0.09, 0.91).

\section{Discussion}

Consistent with reports of increasingly widespread use of communication technology in society, patients in this study reported using a wide variety of communication technologies in their daily activities [18]. At least half of the patients in this study reported using some technologies such as computers, the internet, and the telephone (including text messaging) to manage their health. This finding is consistent with reported trends of individuals' rapidly increasing uptake of technology, such as the internet, to manage their health [19]. However, only a small proportion of patients were interested in using new technologies that they were not currently using in general daily activities in managing their health. The reluctance to utilise more technology-enabled approaches in the context of healthcare may be indicative of a lack of experience with the technology for health management [20-22], and concerns about privacy $[22,23]$. It may also be reflective of an older demographic of patients who may have misconceptions about the difficulty of using technology, or issues with trust [24].

Our findings show differences in patient preferences for communicating with the healthcare team posthospital discharge following a planned admission. Nearly $60 \%$ of patients preferred to return to hospital to communicate about symptoms that were of concern to them, but at least 30\% preferred to communicate via telephone. If patients experienced symptoms that did not cause them concern, two-thirds preferred to use either telephone or other technology to communicate with the health service. These results may suggest that many patients would prefer not to return to the hospital for follow-up unless they were experiencing symptoms of concern. Our findings should not only prompt renewed interest in the role of follow-up telephone calls for patients discharged from the hospital [25] but the role of virtual follow-up visits with health services [26].

In the current study, having a cardiac condition was associated with preferencing in-person communication over a telephone call. Having a gastrointestinal condition was also associated with a decreased preference for using technology to communicate when concerned about 


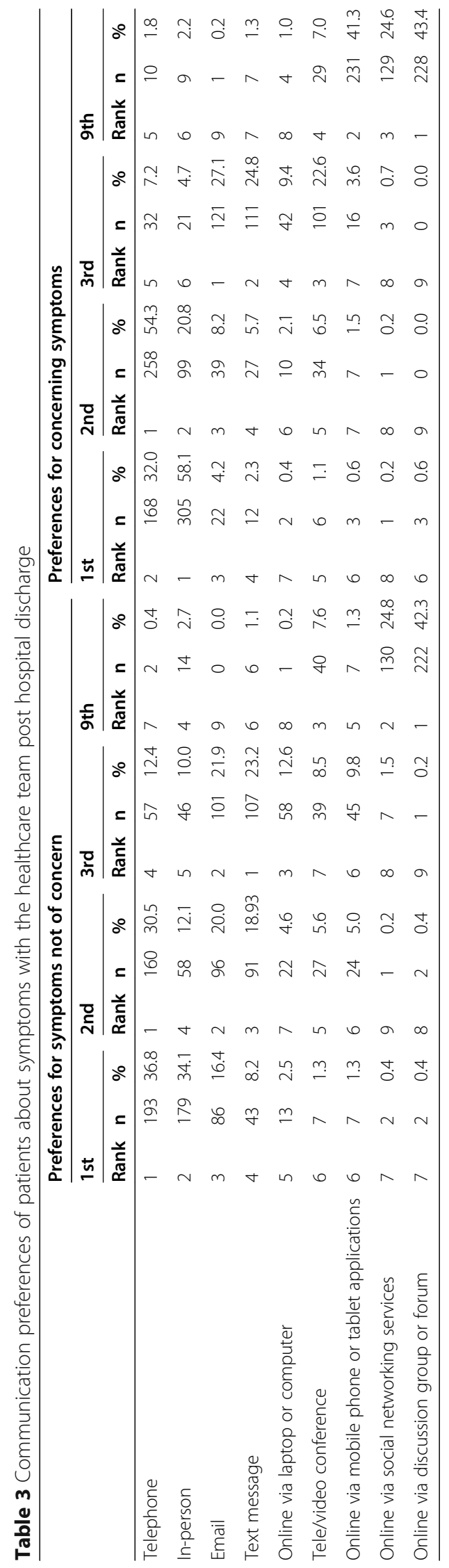


Table 4 Characteristics associated with preferences for communicating about symptoms post hospital discharge

\begin{tabular}{|c|c|c|c|c|c|c|c|c|c|c|c|c|c|c|c|c|c|}
\hline \multirow[t]{3}{*}{ Characteristic } & & \multicolumn{8}{|c|}{ Preferences for symptoms not of concern } & \multicolumn{8}{|c|}{ Preferences for symptoms of concern } \\
\hline & & \multicolumn{2}{|c|}{$\begin{array}{l}\text { In- } \\
\text { person }\end{array}$} & \multicolumn{2}{|c|}{ Telephone } & \multicolumn{2}{|c|}{ Technology ${ }^{a}$} & \multirow[t]{2}{*}{$x^{2}$} & \multirow[t]{2}{*}{ Sig. } & \multicolumn{2}{|c|}{$\begin{array}{l}\text { In- } \\
\text { person }\end{array}$} & \multicolumn{2}{|c|}{ Telephone } & \multicolumn{2}{|c|}{ Technology ${ }^{a}$} & \multirow[t]{2}{*}{$x^{2}$} & \multirow[t]{2}{*}{ Sig. } \\
\hline & & $\mathbf{n}$ & $\%$ & $\mathbf{n}$ & $\%$ & $\mathbf{n}$ & $\%$ & & & $n$ & $\%$ & $\mathbf{n}$ & $\%$ & $\mathbf{n}$ & $\%$ & & \\
\hline \multirow[t]{2}{*}{ Gender } & Male & 95 & 38.9 & 84 & 34.4 & 65 & 26.6 & 3.63 & 0.16 & 145 & 59.4 & 70 & 28.7 & 29 & 11.9 & 1.35 & 0.51 \\
\hline & Female & 73 & 30.7 & 92 & 38.7 & 73 & 30.7 & & & 139 & 58.4 & 77 & 32.4 & 22 & 9.2 & & \\
\hline \multirow[t]{5}{*}{ Age group (years) } & $18-30$ & 8 & 28.6 & 8 & 28.6 & 12 & 42.9 & 26.44 & 0.001 & 21 & 75.0 & 6 & 21.4 & 1 & 3.6 & 11.59 & 0.17 \\
\hline & $31-50$ & 27 & 27.8 & 39 & 40.2 & 31 & 32.0 & & & 61 & 62.9 & 26 & 26.8 & 10 & 10.3 & & \\
\hline & $51-65$ & 43 & 31.6 & 39 & 28.7 & 54 & 39.7 & & & 87 & 64.0 & 37 & 27.2 & 12 & 8.8 & & \\
\hline & $66-80$ & 60 & 44.4 & 51 & 37.8 & 24 & 17.8 & & & 73 & 54.1 & 48 & 35.6 & 14 & 10.4 & & \\
\hline & $81+$ & 10 & 43.5 & 11 & 47.8 & 2 & 8.7 & & & 9 & 39.1 & 12 & 52.2 & 2 & 8.7 & & \\
\hline \multirow[t]{3}{*}{ Geographic area } & Metro & 128 & 36.3 & 126 & 35.7 & 99 & 28.0 & 1.11 & 0.89 & 219 & 62.0 & 104 & 29.5 & 30 & 8.5 & 7.04 & 0.13 \\
\hline & Inner Regional & 30 & 30.6 & 38 & 38.8 & 30 & 30.6 & & & 53 & 54.1 & 30 & 30.6 & 15 & 15.3 & & \\
\hline & $\begin{array}{l}\text { Outer Regional/ } \\
\text { Remote }\end{array}$ & 10 & 34.5 & 11 & 37.9 & 8 & 27.6 & & & 13 & 44.8 & 12 & 41.4 & 4 & 13.8 & & \\
\hline \multirow{5}{*}{$\begin{array}{l}\text { Condition requiring } \\
\text { treatment }\end{array}$} & Orthopaedic & 43 & 30.3 & 57 & 40.1 & 42 & 29.6 & 18.66 & 0.02 & 74 & 52.1 & 45 & 31.7 & 23 & 16.2 & 19.15 & 0.01 \\
\hline & Cardiac & 39 & 52.0 & 15 & 20.0 & 21 & 28.0 & & & 51 & 68.0 & 18 & 24.0 & 6 & 8.0 & & \\
\hline & Oncological & 11 & 26.8 & 18 & 43.9 & 12 & 29.3 & & & 19 & 46.3 & 18 & 43.9 & 4 & 9.8 & & \\
\hline & Gastrointestinal & 33 & 29.7 & 45 & 40.5 & 33 & 29.7 & & & 76 & 68.5 & 30 & 27.0 & 5 & 4.5 & & \\
\hline & Other & 31 & 41.9 & 28 & 37.8 & 15 & 20.3 & & & 47 & 63.5 & 22 & 29.7 & 5 & 6.8 & & \\
\hline \multirow[t]{2}{*}{ Planned treatment } & Surgery & 95 & 29.1 & 129 & 39.6 & 102 & 31.3 & 14.74 & 0.001 & 196 & 60.1 & 98 & 30.1 & 32 & 9.8 & 0.78 & 0.68 \\
\hline & $\begin{array}{l}\text { Investigation/ } \\
\text { medical care }\end{array}$ & 72 & 47.1 & 46 & 30.1 & 35 & 22.9 & & & 88 & 57.5 & 46 & 30.1 & 19 & 12.4 & & \\
\hline \multirow{3}{*}{$\begin{array}{l}\text { Highest Educational } \\
\text { Training }\end{array}$} & School & 86 & 37.6 & 86 & 37.6 & 57 & 24.9 & 5.36 & 0.25 & 121 & 52.8 & 80 & 34.9 & 28 & 12.2 & 7.04 & 0.13 \\
\hline & Vocational & 45 & 29.2 & 57 & 37.0 & 52 & 33.8 & & & 89 & 57.8 & 48 & 31.2 & 17 & 11.0 & & \\
\hline & Tertiary & 44 & 33.6 & 44 & 33.6 & 43 & 32.8 & & & 88 & 67.2 & 32 & 24.4 & 11 & 8.4 & & \\
\hline \multirow[t]{3}{*}{ Employment } & Employed & 85 & 29.9 & 98 & 34.5 & 101 & 35.6 & 20.38 & $\begin{array}{l}< \\
0.001\end{array}$ & 176 & 62.0 & 74 & 26.1 & 34 & 12.0 & 8.16 & 0.09 \\
\hline & Unemployed & 2 & 10.5 & 9 & 47.4 & 8 & 42.1 & & & 9 & 47.4 & 7 & 36.8 & 3 & 15.8 & & \\
\hline & Retired & 88 & 41.9 & 80 & 38.1 & 42 & 20.0 & & & 113 & 53.8 & 78 & 37.1 & 19 & 9.0 & & \\
\hline \multirow{2}{*}{$\begin{array}{l}\text { Annual Household } \\
\text { Income (AUD) }\end{array}$} & $<100,000$ & 115 & 36.6 & 111 & 35.4 & 88 & 28.0 & 9.90 & 0.01 & 179 & 57.0 & 102 & 32.5 & 33 & 10.5 & 1.49 & 0.48 \\
\hline & $\geq 100,000$ & 34 & 22.4 & 62 & 40.8 & 56 & 36.8 & & & 93 & 61.2 & 41 & 27.0 & 18 & 11.8 & & \\
\hline \multirow[t]{2}{*}{ Living arrangements } & Lives with others & 161 & 35.3 & 161 & 35.3 & 134 & 29.4 & 1.93 & 0.38 & 271 & 59.4 & 134 & 29.4 & 51 & 11.2 & 4.96 & 0.08 \\
\hline & Lives alone & 15 & 26.3 & 24 & 42.1 & 18 & 31.6 & & & 27 & 47.4 & 25 & 43.9 & 5 & 8.8 & & \\
\hline \multirow[t]{2}{*}{ Children at home } & No & 135 & 34.4 & 141 & 35.9 & 117 & 29.8 & 0.14 & 0.93 & 221 & 56.2 & 128 & 32.6 & 44 & 11.2 & 2.31 & 0.31 \\
\hline & Yes & 41 & 33.6 & 46 & 37.7 & 35 & 28.7 & & & 78 & 63.9 & 32 & 26.2 & 12 & 9.8 & & \\
\hline Elders at home & No & 162 & 33.4 & 177 & 36.5 & 146 & 30.1 & 2.51 & 0.29 & 280 & 57.7 & 149 & 30.7 & 56 & 11.5 & 3.94 & 0.14 \\
\hline & Yes & 14 & 46.7 & 10 & 33.3 & 6 & 20.0 & & & 19 & 63.3 & 11 & 36.7 & 0 & 0.0 & & \\
\hline
\end{tabular}

${ }^{a}$ The technology category consists of email, text message, online via laptop or computer, tele/video conference, online via mobile phone or tablet applications, online via social networking services, online via discussion group or forum

symptoms. Perhaps the experience of specific conditions is associated with higher treatment-seeking behaviour and the need for more urgent attention. Tran and colleagues [27] found that patients with concerns about cardiac symptoms were more likely to self-present to the emergency department despite receiving telephone review and health helpline advice that their symptoms were of 'low urgency' and 'require self-care'. All orthopaedic patients received a planned surgical intervention. While all the other conditions where planned as well, the reasons for admission were mixed (i.e., surgical, investigation and medical). Patients with a cardiac condition may feel more acutely at risk of rapid deterioration, and perhaps this finding reflects the perceptions of the anticipated possible outcomes between conditions. If true, this highlights the importance of pre-admission 
Table 5 Multivariable analysis of characteristics associated with preferences for communicating by telephone or by using technology compared to in-person communication about symptoms post hospital discharge

\begin{tabular}{|c|c|c|c|c|c|c|c|}
\hline \multirow[t]{2}{*}{ Characteristic } & & \multicolumn{3}{|c|}{$\begin{array}{l}\text { Telephone compared to In-Person } \\
\text { Communication }\end{array}$} & \multicolumn{3}{|c|}{ 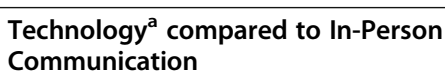 } \\
\hline & & RRR & $\mathrm{Cl} 95 \%$ & Sig. & RRR & $\mathrm{Cl} 95 \%$ & Sig. \\
\hline \multicolumn{8}{|c|}{ Preferences for symptoms not of concern $(n=341)$} \\
\hline \multirow[t]{2}{*}{ Gender } & Male & REF & & & REF & & \\
\hline & Female & 1.24 & $0.71,2.17$ & 0.45 & 1.09 & $0.61,1.94$ & 0.77 \\
\hline \multirow[t]{5}{*}{ Age } & $18-30$ & 0.47 & $0.12,1.81$ & 0.27 & 1.15 & $0.38,3.47$ & 0.81 \\
\hline & $31-50$ & 0.88 & $0.41,1.88$ & 0.73 & 0.65 & $0.30,1.41$ & 0.28 \\
\hline & $51-65$ & REF & & & REF & & \\
\hline & $66-80$ & 0.98 & $0.49,1.97$ & 0.96 & 0.40 & $0.19,0.83$ & 0.01 \\
\hline & $81+$ & 2.32 & $0.70,7.74$ & 0.17 & 0.33 & $0.06,1.83$ & 0.21 \\
\hline \multirow[t]{5}{*}{ Condition requiring treatment } & Orthopaedic & REF & & & REF & & \\
\hline & Cardiac & 0.19 & $0.08,0.45$ & $<0.0001$ & 0.50 & $0.22,1.13$ & 0.10 \\
\hline & Oncological & 0.90 & $0.32,2.50$ & 0.84 & 1.14 & $0.38,3.45$ & 0.81 \\
\hline & Gastrointestinal & 0.67 & $0.32,1.39$ & 0.28 & 0.70 & $0.31,1.45$ & 0.31 \\
\hline & Other & 0.44 & $0.20,0.98$ & 0.05 & 0.45 & $0.18,1.08$ & 0.07 \\
\hline \multirow[t]{3}{*}{ Annual Household Income (AUD) } & $<100,000$ & REF & & & REF & & \\
\hline & $\geq 100,000$ & 2.43 & $1.25,4.74$ & 0.01 & 2.09 & $1.08,4.07$ & 0.03 \\
\hline & & OR & Cl 95\% & Sig. & OR & $\mathrm{Cl} 95 \%$ & Sig. \\
\hline \multicolumn{8}{|c|}{ Preferences for symptoms of concern ( $n=382$ ) } \\
\hline \multirow[t]{2}{*}{ Gender } & Male & REF & & & REF & & \\
\hline & Female & 1.23 & $0.77,1.97$ & 0.39 & 0.97 & $0.45,2.10$ & 0.94 \\
\hline \multirow[t]{5}{*}{ Age } & $18-30$ & 0.36 & $0.10,1.30$ & 0.12 & 0.55 & $0.06,4.70$ & 0.58 \\
\hline & $31-50$ & 0.95 & $0.50,1.78$ & 0.87 & 1.44 & $0.52,3.95$ & 0.48 \\
\hline & $51-65$ & REF & & & REF & & \\
\hline & $66-80$ & 1.45 & $0.82,2.57$ & 0.20 & 1.28 & $0.50,3.33$ & 0.62 \\
\hline & $81+$ & 2.72 & $1.01,7.34$ & 0.05 & 1.70 & $0.31,9.31$ & 0.54 \\
\hline \multirow[t]{5}{*}{ Condition } & Orthopaedics & REF & & & REF & & \\
\hline & Cardiology & 0.53 & $0.26,1.09$ & 0.08 & 0.62 & $0.22,1.78$ & 0.37 \\
\hline & Oncology & 1.19 & $0.53,2.65$ & 0.68 & 0.95 & $0.27,3.33$ & 0.94 \\
\hline & Gl & 0.69 & $0.37,1.28$ & 0.24 & 0.28 & $0.09,0.91$ & 0.04 \\
\hline & Other & 0.71 & $0.36,1.42$ & 0.34 & 0.43 & $0.13,1.40$ & 0.16 \\
\hline
\end{tabular}

RRR Relative Risk Ratio, REF Referent group (largest category), ${ }^{a}$ The technology category consists of email, text message, online via laptop or computer, tele/video conference, online via mobile phone or tablet applications, online via social networking services, online via discussion group or forum

education about the possible outcomes and actions to be taken post-discharge [28, 29]. Research on technology use in healthcare has predominantly focused on the experiences of patients with particular conditions and on patients that have used technology [24]. In this study, we sought to understand the preferences of both those who do and who do not currently use technology in daily life and health management. Investigation of experiences across different conditions warrants further investigation in order to inform appropriate health service responses for patients with a variety of conditions.

Income may affect preferences for communicating about symptoms that are not of concern post-hospital discharge. Patients that reported earning over 100,000 AUD per household per year were more likely than respondents with lower incomes to prefer to use telephone or technology-enabled forms of communication. Earning over 100,000 AUD per household per year was also associated with having higher educational qualifications in this study. Higher-income and education have been previously associated with greater technology use to manage health, such as patient portals [30] and smartphone applications [31]. Some have suggested that there is an emerging 'digital divide' where patients that lack access to computers and smartphones for a variety of reasons could miss out on health innovations that use digital 
technology [32]. However, a recent review (albeit of few studies) reported no associations with patient characteristics (including income) and digital health tool use [33].

Age was significantly associated with different preferences in communication about symptoms. Older people were less likely to prefer using technology over attending in-person when they had symptoms not of concern. It has been reported previously that younger people are more likely to be users of mobile health applications [31], and older persons are less likely to access and use the internet. However, older people were more likely to prefer making a telephone call over attending in-person when they had a concerning symptom. This finding may be because older people have had more experience with illnesses and have had more time to develop an understanding of their conditions and health services [34-36]. Alternatively, older persons may seek to negotiate a delay in admission to the hospital [37]. One review of health-related decision-making in older adults found that limited research in this area exists, however, delays in treatment-seeking by older persons were noted [38]. The desire to remain independent, the influence of others, availability and perceptions of health services available, and having access to information may also affect decisions to seek treatment [39].

Several limitations should be considered in the interpretation of the results of this study. These results represent a small proportion of patients presenting for a planned admission at a metropolitan hospital that predominantly performs surgical or investigational procedures. Therefore, the preferences for communication may not be generalisable to other patients with either different characteristics, those receiving different types of interventions, or those receiving care at different facilities. There was a low completion rate compared to the number of patients admitted during the time of the survey. As participation in the study was voluntary, the results of this study may be biased towards patients that were more interested in the topic, those with more time in the admission area, and those less distracted or concerned by the admission. Data about the characteristics of non-respondents was not available for comparison. Therefore, there may be alternative views of the target sample population that are not represented in the results of this study. As understanding patient preferences for communicating with health service providers through digital technologies is an emerging topic, a review to standardise terms is encouraged to enable future studies to be compared. Differentiating types of communication (e.g. email, website) from the devise used (e.g. mobile phone, laptop) would also allow for a greater understanding of preferencing among those who prefer using technology to communicate with the healthcare team. Future research should measure actual behaviours and reasons for choice in communication with hospitals post-hospital discharge if alternative technologies are made available. It should also consider understanding a broader range of reasons patients may have for contacting health service providers and patient characteristics that may be amenable to facilitating the adoption of technology in healthcare. Differences in technology availability and utilisation across different hospital facilities should also be investigated.

\section{Implications for practice}

The role of the patient partnering with health services is an evolving concept that is increasingly recognised as integral to the delivery of patient-centred and quality healthcare [24]. The use of technology in health will continue to expand, but this study highlights the need for considering the needs and preferences of patients for communicating about their health needs. As health services continue to develop, the move away from a paternalistic system towards self-advocacy, empowerment, and quality is likely to see patients demand increased choice and control about how and when they communicate with healthcare providers [40]. Our study here highlights that acceptance of technology for communication about health is not pervasive, and that service development should also be informed by the needs and preferences of the patients they serve. In addition, these findings perhaps signal that most patients may prefer not to return to hospital for routine follow-up care if they have little or no concerns about their recovery. Health services with protocols requiring in-person follow-up care when recovery is progressing as planned should re-evaluate this practice.

\section{Conclusion}

This is the first study to evaluate for patient preferences for using ICTs to facilitate communication between patients and health service providers following their discharge from hospital. We found patients presenting for a planned admission to hospital use a variety of technologies to manage their daily activities and health. Patients also had preferences that varied depending on their concerns for communicating with the healthcare team posthospital discharge. It demonstrates that some, but not all, patients may prefer to use technology to traditional methods for communicating with the healthcare team post-hospital discharge. The majority of patients currently prefer more traditional methods for communication about symptoms post-hospital discharge (i.e., inperson or by telephone). Preferencing not to visit the hospital in-person is preferred when symptoms experienced are not of concern to a patient. These findings are important in the context of increased pressure to use technology to deliver healthcare efficiencies. These 
findings reinforce that health services should offer patients multiple options for communicating about their recovery to ensure individual needs are met appropriately. To fully realise the potential for greater service delivery efficiency and enhanced patient satisfaction with the healthcare experience that ICT may provide, health services looking to introduce new technologies to assist people with their symptom management should collaborate with patients to ensure such investments are warranted and adopted.

\section{Supplementary Information}

The online version contains supplementary material available at https://doi. org/10.1186/s12913-021-06119-7.

Additional file 1.

\section{Abbreviations}

ICT: Information and communication technology; ePROMs: Electronic patientreported outcome measures; EMR: Electronic medical record; RRR: Relative Risk Ratio; Cl: Confidence Interval

\section{Acknowledgements}

The authors thank the many patients for participating, the contribution made by Ms. Jennifer Barralet to the project set-up, and the hospital and staff members for enabling this project.

\section{Authors' contributions}

K.A. devised the project, conducted the analysis, interpreted the results, and contributed to the writing of the manuscript. H.H. acquired the data for the study and contributed to the writing of the manuscript. T. O contributed to the analysis of the results and to the writing of the manuscript. L. L and N. B, aided in interpreting the results and revising the manuscript. All authors read and approved the final manuscript.

\section{Funding}

Funding for the research was provided by the authors respective institutions (i.e., the Queensland University of Technology and St Vincent's Private Hospital Northside). The funding bodies had no role in the study design, data collection analysis, interpretation, or writing of the manuscript.

\section{Availability of data and materials}

The datasets used and analysed during the current study are available from the corresponding author on reasonable request.

\section{Ethics approval and consent to participate}

Human research ethics approval was obtained from St Vincent's Health and Aged Care Human Research Ethics Committee (HREC 17/25) and administrative review approval was obtained from the Queensland University of Technology Human Research Ethics Committee. Participants were given verbal and written information about the study and provided with a survey. Verbal and implied consent was obtained from all participants. Patients interested in participating did so by voluntarily and anonymously completing the survey and returning it to the research team via collection boxes. This form of informed consent was used because of the low-risk nature of the study, to reduce time pressures in participation, and to ensure participant anonymity. A waiver of written consent was approved by the Human Research Ethics Committee and met national regulations (i.e., the $\mathrm{Na-}$ tional Statement on Ethical Conduct in Human Research (2007) (National Statement (2007)).

\section{Consent for publication}

Not applicable.

\section{Competing interests}

The authors declare that they have no competing interests.
Received: 29 July 2020 Accepted: 25 January 2021

Published online: 15 February 2021

\section{References}

1. Mamlin BW, Tierney WM. The promise of information and communication Technology in Healthcare: extracting value from the chaos. Am J Med Sci. 2016;351(1):59-68.

2. Ross J, Stevenson F, Lau R, Els M. Factors that influence the implementation of e-health: a systematic review of systematic reviews (an update). Implement Sci. 2016;11(1):146.

3. Roberts NA, Alexander K, Wyld D, Janda M. What is needed by staff to implement PROMs into routine oncology care? A qualitative study with the multi-disciplinary team. Eur J Cancer Care. 2019;28(6):e13167.

4. Palacholla RS, Fischer N, Coleman A, Agboola S, Kirley K, Felsted J, et al. Provider- and patient-related barriers to and facilitators of digital health technology adoption for hypertension management: scoping review. JMIR Cardio. 2019;3(1):e11951.

5. Gagnon MP, Ngangue P, Payne-Gagnon J, Desmartis M. M-health adoption by healthcare professionals: a systematic review. Journal of the American Medical Informatics Association : JAMIA. 2016;23(1):212-20.

6. Koivunen M, Saranto K. Nursing professionals' experiences of the facilitators and barriers to the use of telehealth applications: a systematic review of qualitative studies. Scand J Caring Sci. 2018;32(1):24-44.

7. Manias E, Bucknall T, Wickramasinghe N, Gray K, Schaffer J, Rosenfeld E. Patient and family engagement in communicating with electronic medical records in hospitals: a systematic review. Int J Med Inform. 2020;134:104036.

8. Joseph-Shehu EM, Ncama BP, Mooi N, TPJBo M-T. The use of information and communication technologies to promote healthy lifestyle behaviour: a systematic scoping review. BMJ Open. 2019;9(10):e029872.

9. Jensen ER, Rothrock EN, Dewitt ME, Spiegel AB, Tucker MC, Crane BH, et al. The role of technical advances in the adoption and integration of patientreported outcomes in clinical care. Med Care. 2015;53(2):153-9.

10. Smith AC, Thomas E, Snoswell CL, Haydon H, Mehrotra A, Clemensen J, et al. Telehealth for global emergencies: Implications for coronavirus disease 2019 (COVID-19). J Telemed Telecare. 2020;26(5):309-13 1357633X20916567.

11. Holmes MM, Lewith G, Newell D, Field J, Bishop F. The impact of patientreported outcome measures in clinical practice for pain: a systematic review. Qual Life Res. 2017;26(2):245-57.

12. Wintner LM, Giesinger JM, Zabernigg A, Rumpold G, Sztankay M, Oberguggenberger AS, et al. Evaluation of electronic patient-reported outcome assessment with cancer patients in the hospital and at home. BMC Med Inform Decis Making. 2015;15(108):110.

13. Coons S, Eremenco S, Lundy J, O'Donohoe P, O'Gorman H, Malizia W. Capturing patient-reported outcome (PRO) data electronically: the past, present, and promise of ePRO measurement in clinical trials. Patient. 2015; 8(4):301-9.

14. Newnham H, Barker A, Ritchie E, Hitchcock K, Gibbs H, Holton S. Discharge communication practices and healthcare provider and patient preferences, satisfaction and comprehension: a systematic review. Int J Qual Health Care. 2017;29(6):752-68.

15. Chérrez-Ojeda I, Vanegas E, Felix M, Mata VL, Gavilanes AW, Chedraui P. Use and preferences of information and communication technologies in patients with hypertension: a cross-sectional study in Ecuador. J Multidiscip Healthc. 2019;12:583-90.

16. Epstein K, Juarez E, Loya K, Gorman MJ, Singer A. Frequency of new or worsening symptoms in the posthospitalization period. J Hosp Med. 2007; 2(2):58-68.

17. Kruse CS, Krowski N, Rodriguez B, Tran L, Vela J, Brooks M. Telehealth and patient satisfaction: a systematic review and narrative analysis. BMJ Open. 2017;7(8):e016242.

18. Australian Bureau of Statistics. 8146.0 - Household Use of Information Technology, Australia, 2014-15 2016 [Available from: http://www.abs.gov. au/ausstats/abs@.nsf/mf/8146.0.

19. Greenberg AJ, Serrano KJ, Thai CL, Blake KD, Moser RP, Hesse BW, et al. Public use of electronic personal health information: measuring progress of the healthy people 2020 objectives. Health Policy Technol. 2017;6(1):33-9.

20. Heinz MMS, Martin PP, Margrett JAP, Yearns MP, Franke WP, Yang H-IP, et al. Perceptions of technology among older adults. J Gerontol Nurs. 2013;39(1): 42-51.

21. Walsh K, Callan A. Perceptions, preferences, and acceptance of information and communication Technologies in Older-Adult Community Care Settings 
in Ireland: a case-study and ranked-care program analysis. Ageing Int. 2011; 36(1):102-22.

22. Kruse CS, Argueta DA, Lopez L, Nair A. Patient and provider attitudes toward the use of patient portals for the management of chronic disease: a systematic review. J Med Internet Res. 2015;17(2):e40.

23. Martínez-Pérez B, de la Torre-Díez I, López-Coronado M. Privacy and security in Mobile health apps: a review and recommendations. J Med Syst. 2014; 39(1):181.

24. Bradford NK, Caffery $\sqcup$, Smith AC. Awareness, experiences and perceptions of telehealth in a rural Queensland community. BMC Health Serv Res. 2015; 15(1):427.

25. Ma Y, Jones G, Tay YK, Hunter T, Holden D, Rodgers-Wilson S, et al. Postoperative telephone review is safe and effective: prospective study Monash outpatient review by phone trial. ANZ J Surg. 2018;88(5):434-9.

26. Healy P, McCrone L, Tully R, Flannery E, Flynn A, Cahir C, et al. Virtual outpatient clinic as an alternative to an actual clinic visit after surgical discharge: a randomised controlled trial. BMJ Qual Saf. 2019;28(1):24-31.

27. Tran DT, Gibson A, Randall D, Havard A, Byrne M, Robinson M, et al. Compliance with telephone triage advice among adults aged 45 years and older: an Australian data linkage study. BMC Health Serv Res. 2017;17(1):512.

28. Powell R, Scott NW, Manyande A, Bruce J, Vogele C, Byrne-Davis LM, et al. Psychological preparation and postoperative outcomes for adults undergoing surgery under general anaesthesia. Cochrane Database Syst Rev. 2016;5:Cd008646.

29. Rees S, Williams A. Promoting and supporting self-management for adults living in the community with physical chronic illness: a systematic review of the effectiveness and meaningfulness of the patient-practitioner encounter. JBI Library Syst Rev. 2009;7(13):492-582.

30. Osborn CY, Mayberry LS, Wallston KA, Johnson KB, Elasy TA. Understanding patient portal use: implications for medication management. J Med Internet Res. 2013;15(7):e133.

31. Carroll JK, Moorhead A, Bond R, LeBlanc WG, Petrella RJ, Fiscella K. Who uses Mobile phone health apps and does use matter? A secondary data analytics approach. J Med Internet Res. 2017;19(4):e125.

32. Nguyen A, Mosadeghi S, Almario CV. Persistent digital divide in access to and use of the internet as a resource for health information: results from a California population-based study. Int J Med Inform. 2017;103:49-54.

33. Nouri SS, Adler-Milstein J, Thao C, Acharya P, Barr-Walker J, Sarkar U, et al. Patient characteristics associated with objective measures of digital health tool use in the United States: a literature review. J Am Med Inform Assoc. 2020;27(5):834-41.

34. Mitzner TL, Boron JB, Fausset CB, Adams AE, Charness N, Czaja SJ, et al. Older adults talk technology: technology usage and attitudes. Comput Hum Behav. 2010;26(6):1710-21.

35. Ware P, Bartlett SJ, Paré G, Symeonidis I, Tannenbaum C, Bartlett G, et al. Using eHealth Technologies: Interests, Preferences, and Concerns of Older Adults. Interact J Med Res. 2017;6(1):e3.

36. Dreyer K, Steventon A, Fisher R, Deeny SR. The association between living alone and health care utilisation in older adults: a retrospective cohort study of electronic health records from a London general practice. BMC Geriatr. 2018;18(1):269.

37. Dyrstad DN, Laugaland KA, Storm M. An observational study of older patients' participation in hospital admission and discharge--exploring patient and next of kin perspectives. J Clin Nurs. 2015;24(11-12):1693-706.

38. King L, Harrington A, Linedale E, Tanner E. A mixed methods thematic review: health-related decision-making by the older person. J Clin Nurs. 2018;27(7-8):e1327-e43.

39. Cheek J, Ballantyne A, Roder-Allen G, Jones J. Making choices: how older people living in independent living units decide to enter the acute care system. Int J Nurs Pract. 2005;11(2):52-7.

40. McGrath PJTP-P-COR. Technology-based patient consultations: research findings from haematology patients in regional, rural and remote Queensland. Patient. 2015;8(2):199-206.

\section{Publisher's Note}

Springer Nature remains neutral with regard to jurisdictional claims in published maps and institutional affiliations.

\section{Ready to submit your research? Choose BMC and benefit from}

- fast, convenient online submission

- thorough peer review by experienced researchers in your field

- rapid publication on acceptance

- support for research data, including large and complex data types

- gold Open Access which fosters wider collaboration and increased citations

- maximum visibility for your research: over $100 \mathrm{M}$ website views per year

At BMC, research is always in progress.

Learn more biomedcentral.com/submissions 